Dorota Dąbrowska

10.15290/cr.2016.13.2.01

University of Warsaw

\title{
A multimodal perspective on metaphors and metonymies in art: \\ A case study of the artwork Agora by Magdalena Abakanowicz
}

\begin{abstract}
The article is a semiotic study of the artistic installation Agora designed by a famous Polish sculptor Magdalena Abakanowicz, based on the theoretical grounds of Cognitive Semantics. Metaphor and metonymy are conceptual processes whose communicative function is discussed in the paper, in particular, their role in deciphering possible meanings of the artwork. The paper also demonstrates how the multimodal analysis of the verbo-visual material can give rise to diverse interpretations of the figures.
\end{abstract}

Keywords: cognitive semantics, metaphor, metonymy, art.

\section{Introduction}

This paper presents a semiotic analysis of the artwork Agora created by a renowned Polish artist Magdalena Abakanowicz. Agora is a sculptural installation, located in Grant Park in Chicago in The United States, and it is one of the biggest figural compositions of the artist. The artwork presents 106 iron figures, with the title inscribed on the plate and attached to the stone that is placed in the vicinity of the sculptures.

In the paper the role of cognitive mechanisms of metonymy and metaphor will be discussed, especially their interaction which can lead to different conceptualisations of the installation. The key elements of the artwork that need to be examined to uncover the possible range of meanings are the missing body parts, the composition, and the cultural context. The proposed semantic analysis is divided into two parts: the external perspective that involves the identification of visual metaphors and metonymies of the figural composition, and a slightly different interpretative scenario that results from combining the verbal and visual modalities - an attempt at identifying the multimodal metaphor. 


\section{Metaphor in other modalities}

Although it has long been acknowledged that metaphorical reasoning is a cognitive process present in daily activities (Lakoff and Johnson 1980: 3), for a long time, the research areas concerning the study of metaphor focused on the verbal modality only. The analyses of metaphor in the pictorial and verbo-pictorial discourse introduced and developed by Charles Forceville (1996), led to the increased attention of the conceptual mechanism in other non-linguistic forms. The conducted research has covered modalities such as gesture (Müller 2008; Mittelberg and Waugh 2009), and music (Górska 2014; Zbikowski 2009), with a special focus on the meanings expressed by juxtaposing different modalities, such as e.g: verbo-pictorial (Forceville 1996, 2008), and verbomusical (Górska 2014). Multimodal studies have also been developed in film (Rohdin 2009), TV commercials (Urios-Aparisi 2009), and newspaper cartoons (El Refaie 2009). In this article, the semantic potential of the visual and verbo-visual modalities are discussed and, in particular, the interaction of both codes, whose co-occurrence can affect the interpretation of the artwork.

\section{Analysis}

\subsection{The figural composition}

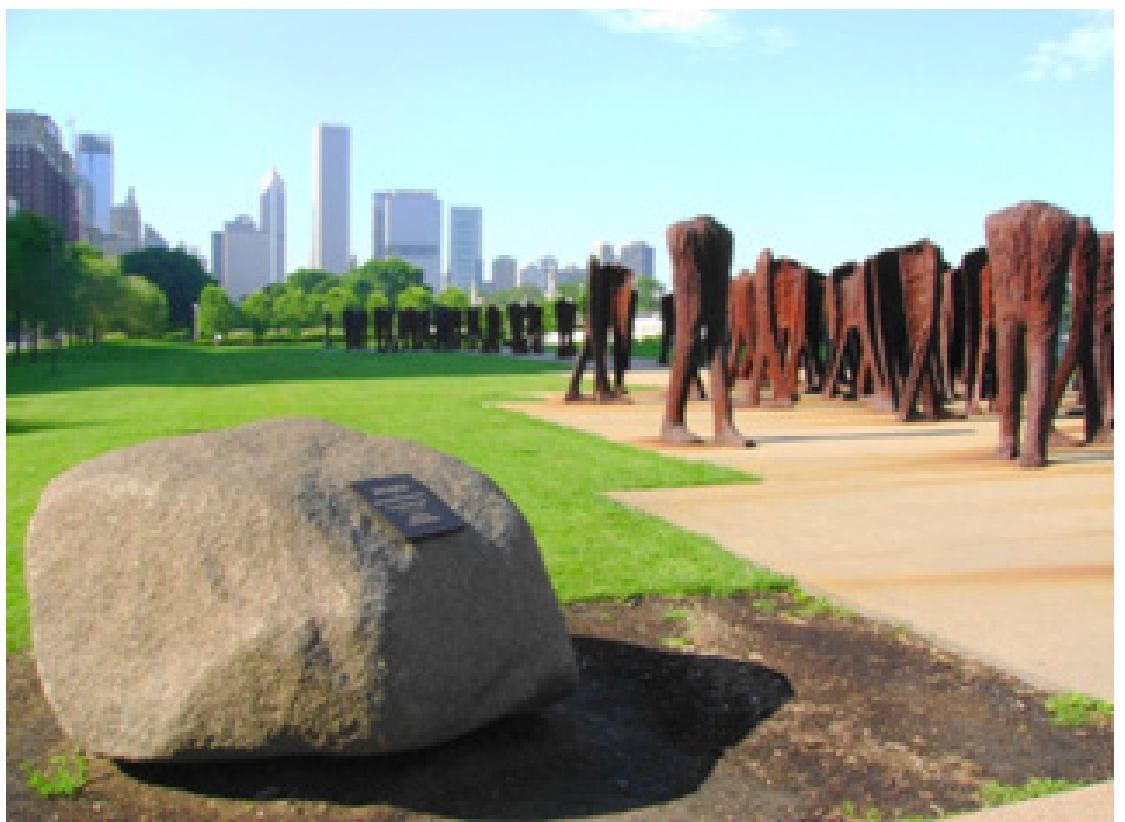

Figure 1. Agora by Magdalena Abakanowicz ${ }^{1}$

The collection of headless human-like sculptures with enlarged bodies, and long legs that support the disproportionately long corpuses can create an impression that the artistic message of what bodily deformations can manifest is of conceptual significance. From a distance the sight of oversized sculptures clustered on a patch of concrete can evoke an image of a mass gathering, which

1 The included photographs are from the author's collection. 
appears to illustrate how a meaning can be expressed via the change of size. The enlargement seems deliberate, and initially, it may suggest the visual manifestation of the conceptual metaphor MORE OF FORM IS MORE OF CONTENT (Lakoff and Johnson 1980: 127), or SIGNIFICANT/IMPORTANT IS BIG (Lakoff and Johnson 1980: 50). Kwiatkowska (2013: 79-91) addresses the role of size in visual art, as one of the forms via which a message can be conveyed, especially how it determines the interpretation of art: "Such magnification allows us to see the object in a new light, which may evoke new associations" (Kwiatkowska 2013: 84). The size of sculptures is magnified, and to access the entire view of the figures from a small distance, the observers need to look up to them, and the visual confrontation with objects which are so massive in posture can produce a sense of fragility and weakness on the part of the observers. Such impressions may manifest the metaphorical reasoning BEING SUBJECT TO CONTROL or FORCE IS DOWN (Lakoff and Johnson 1980: 15).

Metaphor and metonymy form a strong conceptual relation in the artwork Agora, as the metonymic interpretation provides the contextual foundations via which different metaphors can be construed. This is visible in the interpretation of the missing body parts, in particular, the missing heads, as all the figures are deprived of them. Conceptualising the head as a source of intellect can be an example of the "internal metonymy" (for the latter see Mittelberg and Waugh 2009: 335) HEAD FOR INTELLECT, which is an example of the metonymic structure in which a body part represents an abstract concept (see Radden and Kövecses 1999: 46). This "conceptual contiguity" (Mittelberg and Waugh 2009: 340) appears crucial in the process of meaning construction, as the head naturally motivates the CONTAINER FOR CONTAINED metonymy (Kövecses 2002: 156). By entailment, the headless figures can evoke the opposite meaning, such as: LACK OF HEAD FOR LACK OF INTELLECT. The source domain of the metonymy - HEADS is visually absent, and it refers to the abstract target - INTELLECT. Thus, the interpretation of the headless gathering as lacking intellect, or reasoning is arrived at via the metonymic basis. The conceptualisation is also based on the CONTAINER image schema (see Johnson 1987: 22), which structures THE MIND IS A CONTAINER metaphor (Lakoff and Johnson 1980: 214). ${ }^{2}$

Thus, the meaning of the headless figures as manifesting intellectual deficiencies, can dominate in the interpretation. Another conspicuous element in the installation is the visual absence of faces which can indicate an array of meanings as well. First, the face - an indispensable body part involved in a direct act of verbal communication - is not present, which is yet another factor that reinforces the sense of lost ability to communicate and alienation. This property appears important in the context of the artwork, as positioning of the figures in close proximity to each other implies a communicative intention of the gathering. The lack of faces may also signify the lack of individuality, and uniqueness, and the conceptual metonymy in terms of which the meaning can be construct-

\footnotetext{
2 The metaphor has numerous linguistic realizations, such as: "What put that (idea) into your head (= What made you think that)?", “Use your head (= Think more carefully)!” The examples are from the Cambridge International Dictionary of English. 1997. Cambridge: Cambridge University Press: 653. It should also be noted that in other cultures the head can signal other meanings, e.g. in Tunisian Arabic (see Maalej 2014).
} 
ed is THE FACE FOR THE PERSON (Lakoff and Johnson 1980: 37 ), ${ }^{3}$ which is an instantiation of A PART FOR WHOLE metonymy (Lakoff and Johnson 1980: 36). Therefore, the absence of face can add another aspect of meaning to the interpretation of the depicted contemporary Agora, implying anonymity in the crowd, or lack of individuality that results from a double metonymic reading: LACK OF FACE FOR LACK OF INDIVIDUALITY, or LACK OF FACE FOR ANONYMITY.

Other elements of the installation can also reflect particular dysfunctions of human abilities, and they appear to be demonstrated through the missing arms/hands. Arms and hands are typically associated with their physical function, such as grasping, holding objects and also gesturing in communication. ${ }^{4}$ All statues are deprived of these body parts, and this may trigger metonymic reasoning in terms of which the visually inaccessible metonymic source - the hand evokes an activity performed with it, i.e. the metonymy THE HAND STANDS FOR THE ACTIVITY/SKILL (Kövecses 2002: 207). ${ }^{5}$ This metonymic reasoning can be analyzed in terms of the "external metonymy" (Mittelberg and Waugh 2009: 334), and at the same time it is an example of the INSTRUMENT FOR ACTION metonymy (Kövecses 2002: 145).

The absence of hands and arms in the context of the mass gathering may also suggest a failed attempt to build a relation, which implies a strong activation of the LINK image schema (see Johnson 1987: 117). Therefore, the missing limbs can lead to a number of interpretations based on the conceptual mechanism of metonymy such as: LACK OF HANDS FOR LACK OF SKILLS, or LACK OF HANDS FOR LACK OF COOPERATION. Since the lack of the indispensable body parts evokes the lack of mental and physical functions they perform, such metonymic references may imply dysfunctional human relations.

The CONTAINER image-schema (see Johnson 1987: 22), significantly contributes to the meaning of the fleshless statues. A notable element of the sculptural forms is that from the back the casts resemble empty insides, which can give rise to various metaphorical interpretations. According to Kövecses (1990), different emotion concepts are expressed via reference to particular bodily organs which manifests THE BODY IS A CONTAINER FOR THE EMOTIONS metaphor (Kövecses 1990: 122). ${ }^{6}$ The metaphor has culture-specific realizations, as particular body organs can communicate various emotions, which, in the context of the considered artwork, can be a starting point in the interpretation of the artwork. In Western culture, the heart is considered to

3 The metonymy is often used in language, e.g.: "I was greeted by smiling faces" The example is from the Cambridge International Dictionary of English. 1997. Cambridge: Cambridge University Press: 490.

4 Understanding of this body part is also culture-specific and can manifest a number of other meanings, e.g. in Tunisian Arabic (see Maalej 2014).

5 The metonymy is frequently employed in language: "All these toys are made by hand", "Rosie, remember you should always hold my hand when we cross the road". The examples are from the Cambridge International Dictionary of English. 1997. Cambridge: Cambridge University Press: 640.

6 This is a general metaphor which has metonymic basis, e.g. "He got butterflies in the stomach" - the bodily organ metonymically evokes a sense of fear and anxiety via the physical location of the emotions. The example is from Kövecses (1990: 72). 
be an organ with which a number of emotions is associated, and the feeling of love in particular, and the mention of the bodily organ metonymically evokes the feeling. ${ }^{7}$ A different line of reasoning may adopt an individual who speaks, for example, Swahili, in which the heart is also regarded as the physical location of bravery and enthusiasm (see Kraska-Szlenk 2014: 56-57, 65-66; see also Kraska-Szlenk 2005: 162-166). Yet another conceptualisation of the heart is characteristic of Chinese (see Yu 2009), in which the heart is considered to be an origin of human mental skills (see Yu 2009: 126). Thus, for viewers representing different cultural backgrounds, the empty figures deprived of their organs may signal a lost value of different emotions and features that determine life of an individual, which, in turn, may lead to diverse interpretations of the artwork.

The physical organization of the statues also appears symbolic in this artwork, and elements such as the position of the sculptures and the figural composition can affect the interpretation. According to Feng and O'Halloran (2013), the object of conceptualisation often attracts more attention than the visual context: "cognitive studies of visual metaphor mostly focus on what is in the image, instead of how the image is represented" (Feng and O'Halloran 2013: 329). In the considered artwork, compositional factors such as the arrangement and orientation of the statues can be particularly important in the process of interpretation. At a distance, the installation looks like a huge gathering, however, on approaching it, the sculptures are at a particular distance from each other, and depicted as if following individuated paths. The spaces between them can mark an individuated existence and be indicative of a distance, either emotional or social/cultural, which can motivate the metaphor AN EMOTIONAL RELATIONSHIP IS A DISTANCE BETWEEN TWO ENTITIES (Kövecses 2000: 92), and the primary metaphor INTIMACY IS CLOSENESS (Grady 1997: 13; see also Lakoff and Johnson 1999: 50).

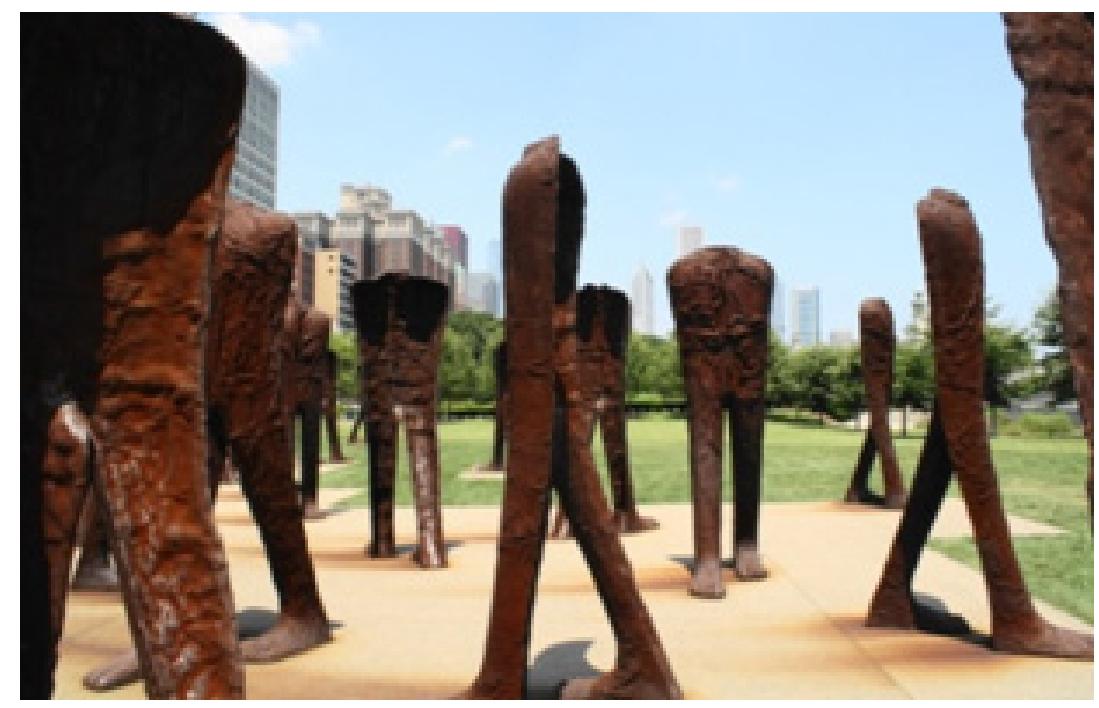

Figure 2. Agora by Magdalena Abakanowicz

7 Such examples are commonly used in language: "He broke her heart (= made her very sad) when he left her for another woman", "I love you with all my heart (= very much)". The examples are from the Cambridge International Dictionary of English. 1997. Cambridge: Cambridge University Press: 656. 
Bodily reactions are visual illustrators of various emotional states (see Kövecses 2000), and the manner of communication is usually reflected by the distance maintained in the physical space. Kövecses (2000: 26) also emphasizes the significance of proximity as an important source concept in metaphorical construals which describe love relationships.

This is in line with Lakoff and Johnson (1999), who also point to the fact that "our bodies define a set of fundamental spatial orientations that we use not only in orienting ourselves, but in perceiving the relationship of one object to another" (Lakoff and Johnson 1999: 34). The physical distance between the statues and their specific positioning can be used metaphorically to imply emotional states or social affiliation, which opens doors to particular metaphorical construals such as: LACK OF EMOTIONAL BONDS/SOCIAL AFFILIATION IS WALKING AN INDIVIDUATED PATH, or ANONYMITY/LACK OF CULTURAL BELONGING IS WALKING IN DIVERSE DIRECTIONS. Bodily orientation of the statues is another important element in the process of interpretation. Regardless of the compacted form of the installation, the lateral or opposite-body orientation of the sculptures can manifest the lack of interest and this can be analyzed in terms of the metaphor LACK OF INTEREST IS THE LATERAL/OPPOSITE BODY ORIENTATION.

The location of Agora - the City of Chicago which is famous for the inflow of emigrants can be regarded as the contextual frame for the interpretation of the artwork. Since emotional bonds and the same cultural backgrounds are usually associated with closeness and togetherness, different bodily orientations of the statues depicted in the walking pose can also reflect the lack of cultural belonging, anonymity in a big city, or a sense of alienation experienced by newcomers who seek good fortune in the metropolis. The spatial organization of statues is very dynamic, manifesting directionality and motion, and the whole composition can be understood as a fraction of a scene, as if a photograph was taken to capture a moment of a fast unfolding action. Thus, the visual composition can also be a manifestation of the primary metaphor PURPOSES ARE DESTINATIONS (Lakoff and Johnson 1999: 61). The sculptures create an impression as if (they were) traversing individuated paths towards a particular destination, where the PATH image schema (see Johnson 1987: 114) structures the complex metaphor A PURPOSEFUL LIFE IS A JOURNEY (Lakoff and Johnson 1999: 60).

\subsection{Integrating the visual and the verbal mode}

Despite a rich array of metaphorical construals based on the missing body parts and the physical organization of the statues, the interpretations may vary depending on whether the viewer is familiar with the title or not. Not seeing the name Agora, or without being aware of what it signifies, the viewer will simply attempt at deciphering the meaning behind the spatial organization of statues and their missing body parts. On recognizing the sense of the title, the visual composition, as a whole, can also serve as an instantiation of a multimodal metaphor (for the latter see Forceville and Urios-Aparisi 2009: 4), where the integration of two different domains leads to a new interpretative form. The knowledge of what the title can activate is a necessary prerequisite to analyse the artwork 
from the multimodal perspective. In that case, the meaning of the title Agora can provide an organizing frame in a multimodal analysis of Abakanowicz's artwork, as it introduces the other (verbal) modality and activates the transfer of properties between the headless gathering and the title.

The name Agora is of Greek origin, ${ }^{8}$ and it means a place where people used to meet to discuss important issues in politics, art and society, and the title of the artwork can be motivated by THE PLACE FOR THE EVENT metonymy (Lakoff and Johnson 1980: 39). Thus, for a history-conscious viewer the historical reference of the title Agora can naturally cause the transfer of properties from the verbal modality presented by the title - Agora, onto the visual modality presented by the human-like statues. The selection of relevant aspects activated by the Greek Agora such as: human gathering, intellectual disputes and philosophical discussions are the salient properties for which the Ancient Agora was famous. When these aspects are mapped onto the visual modality the deformed human bodies, a new conceptualisation is possible.

At the same time, the statues depicted as following individuated paths can provide contrast with the most essential feature of the Ancient Agora, which was the meeting place. The distance between the figures positioned as if travelling towards different destinations/locations can be understood as a visual representation of the fact that the contemporary Agora is no longer a meeting place. This conceptualisation may also imply the concept of loneliness and alienation in a crowd, as the individuated paths and the relative distance between the sculptures may be indicative of a failed attempt to become part of a larger community.

The title may also have a role of "anchorage" (Barthes 1977: 38), as it narrows down the range of interpretations of the figures by identifying their meaning via transferring certain properties of the original meaning of Agora onto the sculptures. Removing the verbal component - the title Agora, would inevitably affect the metaphorical reading of the artwork, as a different meaning is demonstrated through the visual modality and the one expressed verbally. The two modalities are combined together through the integration of the whole visual context; the historical name Agora and the headless statues. It can be assumed that the juxtaposition of the title of the artwork - Ago$\mathrm{ra}$, signalled by the verbal modality, and the sculptures - the visual modality, can be analyzed as a multiple space model in a dynamic meaning creation.

The contiguity relation between the metonymic vehicle and target is of particular significance here; the title Agora is the perceivable metonymic vehicle that may provide the point of access to the metonymic target that is the ancient meeting place: AGORA FOR THE MEETING PLACE. Aspects of the Ancient Agora which can be evoked via the title, such as intellectual meetings are mapped onto the contemporary installation providing grounds for the metaphorical interpretation of the artwork. The selective mapping of aspects from the title onto the figural composition may give rise to an emergent metaphorical construal which can be rendered as: MODERN AGORA IS A HEADLESS CROWD OF PEOPLE MOVING IN DIVERSE DIRECTIONS.

8 See https://www.britannica.com/topic/agora (accessed: 22.04.2017). 


\section{Conclusion}

The article discusses the communicative function of verbo-visual metaphors and metonymies in the interpretation of the piece of art Agora by Magdalena Abakanowicz. These conceptual mechanisms are employed to analyze the artistic message conveyed in the sculptural installation. The interaction of metaphor and metonymy is examined, especially how the semantic potential of this interplay can result in different interpretative forms. A multimodal perspective is also presented through analysing the semantic content that is expressed by two different modalities. It is claimed that the figural composition may involve different meanings, which can be identified via the conceptual processes that facilitate a better understanding of the artwork.

\section{References}

Barthes, Roland. 1977. Image, Music, Text. New York: Hill and Wang.

El Refaie, Elisabeth. 2009. "What Makes Us Laugh? Verbo-Visual Humour in Newspaper Cartoons". In: E. Ventola and A.J. Moya Guijarro (eds.), The World Told and the World Shown, 75-89. New York: Palgrave McMillan.

Feng, D. and O'Halloran, K. L. 2013. “The visual representation of metaphor: A social semiotic approach.” Review of Cognitive Linguistics 11 (2): 320-335.

Forceville, Charles. 1996. Pictorial Metaphor in Advertising. London/New York: Routledge.

Forceville, Charles. 2008. "Metaphor in Pictures and Multimodal Representations". In: R. W. Gibbs (eds), The Cambridge Handbook of Metaphor and Thought, 462-482. Cambridge: Cambridge University Press.

Forceville, Charles and Eduardo Urios-Aparisi. 2009. "Introduction". In: Ch. Forceville and E. Urios-Aparisi (eds.), 2009. Multimodal Metaphor, 3-17. Berlin/New York: Mouton de Gruyter.

Grady, Joseph Edward 1997. Foundations of Meaning: Primary Metaphors and Primary Scenes. Ph.D. dissertation. University of California: Berkeley.

Górska, Elżbieta. 2014. "Why are multimodal metaphors interesting? The perspective of verbovisual and verbo-musical modalities". In: M. Kuźniak, A. Libura and M. Szawerna (eds.), From Conceptual Metaphor Theory to Cognitive Ethnolinguistics. Patterns of Imagery in Language, 17-36. Frankfurt/Main: Peter Lang.

Johnson, Mark. 1987. The Body in the Mind. The Bodily Basis of Meaning, Imagination, and Reason. Chicago: University of Chicago Press.

Kövecses, Zoltán. 1990. Emotion Concepts. New York: Springer-Verlag.

Kövecses, Zoltán. 2000. Metaphor and Emotion: Language, Culture, and Body in Human Feeling. Cambridge/New York: Cambridge University Press.

Kövecses, Zoltán. 2002. Metaphor. A Practical Introduction. Oxford: Oxford University Press.

Kraska-Szlenk, Iwona. 2005. "Metaphor and metonymy in the semantics of body parts: A contrastive analysis". In: E. Górska and G. Radden (eds.), Metonymy-Metaphor Collage, 157-175. Warsaw: Warsaw University Press. 
Kraska-Szlenk, Iwona. 2014. "Extending Body-Part Terms in the Domain of Emotions". In: M. Brenzinger and I. Kraska-Szlenk (eds.), The Body in Language. Comparative Studies of Linguistic Embodiment, 52-70. Leiden/Boston: Brill.

Kwiatkowska, Alina. 2013. Interfaces, Interspaces. Image. Language. Cognition. Piotrków Trybunalski: Naukowe Wydawnictwo Piotrkowskie.

Lakoff, George and Mark Johnson. 1980. Metaphors We Live By. Chicago: The University of Chicago Press.

Lakoff, George and Mark Johnson. 1999. Philosophy in the Flesh: The Embodied Mind and Its Challenge to Western Thought. New York: Basic Books.

Maalej, Zouheir A. 2014. "Body Parts We Live By in Language and Culture: The raas 'head' and yidd 'hand' in Tunisian Arabic". In: M. Brenzinger and I. Kraska-Szlenk (eds.), The Body in Language. Comparative Studies of Linguistic Embodiment, 224-259. Leiden/Boston: Brill.

Mittelberg, Irene and Linda R. Waugh. 2009. "Metonymy first, metaphor second: A cognitive - semiotic approach to multimodal figures of thought in co-speech gesture". In: Ch. Forceville and E. Urios-Aparisi (eds.), Multimodal Metaphor, 329-356. Berlin/New York: Mouton de Gruyter.

Müller, Cornelia. 2008. Metaphors Dead and Alive, Sleeping and Waking. A Dynamic View. Chicago: The University of Chicago Press.

Radden, Günter and Zoltán Kövecses. 1999. “Towards a Theory of Metonymy”. In: K.-U. Panther and G. Radden (eds.), Metonymy in Language and Thought, 17-59. Amsterdam/Philadelphia: John Benjamins.

Rohdin, Mats. 2009. "Multimodal metaphor in classical film theory from the 1920s to the 1950s". In: Ch. Forceville and E. Urios-Aparisi (eds.), Multimodal Metaphor, 403-428. Berlin. Mouton de Gruyter.

Urios-Aparisi, Eduardo. 2009. "Interaction of multimodal metaphor and metonymy in TV commercials: Four case studies". In: Ch. Forceville and E. Urios-Aparisi (eds.), Multimodal Metaphor, 95-117. Berlin/New York: Mouton de Gruyter.

Yu, Ning. 2009. "Nonverbal and multimodal manifestations of metaphors and metonymies: A case study”. In: Ch. Forceville and E, Urios-Aparisi (eds.), Multimodal Metaphor, 119-143. Berlin/ New York: Mouton de Gruyter.

Zbikowski, Lawrence M. 2009. "Music, language, and multimodal metaphor”. In: Ch. Forceville and E. Urios-Aparisi (eds.), Multimodal Metaphor, 359-381. Berlin/New York: Mouton de Gruyter.

\section{Dictionaries and Internet sources}

Cambridge International Dictionary of English. 1997. Cambridge: Cambridge University Press. See https://www.britannica.com/topic/agora (accessed: 22.04.2017). 